\section{Questión}

Periodismo / Comunicación ISSN 1669-6581
- Av. $44 \mathrm{~N}^{\circ} 676,1^{\circ}$ piso

CP 1900 - La Plata - Argentina

www.perio.unlp.edu.ar/question

Volver al Futuro

Guillermo Fernícola

DOI: https://doi.org/10.24215/16696581e283

\title{
Volver al Futuro
}

\section{Back to the Future}

Guillermo Fernícola / gofernicola@gmail.com Contador Público UNLP 1991 - Cursó la Maestría en Direccion en USAL 1999 - Actualmente cursando la Maestría en Ciencia Política de la UNLP - Se desempeñó en el ambito privado en Finanzas hasta 2004 y posteriormente en Comercialización y Publicidad.

Recuerdo vívidamente cuando publiqué en una red social un panfleto bastante incendiario (provocador, ¿por qué no?) y muy desprolijo sobre los efectos transformadores de CoViD-19 en la mirada de las personas acerca de la importancia de lo estatal, en el valor del Estado y su impacto en la vida (o muerte) de los integrantes de la sociedad civil. Eran los tumultuosos tiempos en que todavía se discutía fervientemente sobre si la cuarentena obligatoria impuesta por las autoridades argentinas para combatir la Pandemia era buena o mala, sobre si el Gobierno estaba o no equivocado, hace exactamente 40 días, así de vertiginoso se volvió todo. En esas líneas traté de expresar lo que me parecía más impresionante y era la velocidad y violencia de los cambios que trae esta situación para todos, como individuos y como sociedad: cómo debemos repensar la forma en que se transitan el amor, el trabajo, el ocio, el saber, el poder, a la luz de esta pandemia y de sus consecuencias posteriores.

En aquel momento no lo hice, pero en esta nueva mirada al tema me pareció obligatorio ordenar un poco las ideas y abordar algunos tópicos que sospecho van a formar parte de la agenda del futuro muy cercano. 
Anomia is the new black

Muchos han sido los estudios en sociología que desde el s XIX plantean que el surgimiento del "yo" y de la conciencia es el resultado de una evolución y de la interacción con el ambiente, entre ellos los de George H. Mead, para quien en la formación del individuo es fundamental la interacción con la sociedad y la comunicación con sus semejantes. Nos es familiar el concepto de "individuo como reflejo de la sociedad", la idea de que la persona se forma conciencia de sí en contraste con lo que es capaz de ver, de internalizar sobre las actitudes de los otros.

Casi en paralelo con Mead, otro importante teórico de Fines del S XIX, Emile Durkheim, definía a la sociedad como el conjunto de sentimientos, ideas, creencias y valores que surgen a partir de la organización individual a través de este tipo de grupo y que tiene una existencia diferente y superior a cada uno de sus miembros, es decir, que existe gracias al grupo pero no está en ninguno de ellos de forma individual.

Según Durkheim, dicha sociedad cumple dos funciones: la integración y la regulación; cuando la segunda no es ejercida adecuadamente, los individuos se encontrarán en una situación de anomia, concepto que ocupa un papel central en su obra.

Aunque las ideas y el trabajo de Durkheim sobre anomia se enfocaron principalmente en el suicidio como principal emergente y fueron posteriormente ampliadas, Durkheim realizó un análisis de la transformación de la sociedad como consecuencia del cambio de modelo económico y productivo (en su época esto estaba encarnado por la llegada del capitalismo y la industrialización) en cuyo contexto, las reglas que antes servían para organizar e interpretar al mundo habían dejado de cumplir ese rol y no se estaban "poniendo al día" con suficiente velocidad, dado que la transformación había sido rápida y profunda, la sociedad se encontraba atravesando una crisis transicional debida a que los patrones tradicionales de organización y reglamentación habían quedado atrás y no hubo tiempo suficiente para que surjan otros patrones adaptados a las nuevas necesidades (¿suena familiar?).

A diferencia del amigo Durkheim, otro importante pensador de principios del SXX, Robert K. Merton, no consideraba la naturaleza biológica del ser humano como importante para explicar la desviación, haciendo foco en el orden social. Postulaba una dicotomía entre las metas culturales y los medios institucionales para lograr esas metas y destacaba que el desequilibrio entre las metas culturales y las normas institucionales en una sociedad conducen a un deterioro de la estructura cultural que ocurre en particular cuando hay una marcadas 
discrepancia entre las normas y metas culturales, y las capacidades de los miembros del grupo de comportarse de acuerdo con aquellas, en otras palabras, QUIERO, PERO NO PUEDO. Lo que Merton trataba de explicar no solo era el suicidio, sino también varios tipos de conducta sobrevinientes en un estado de anomia generalizada: el crimen, la delincuencia, los desordenes mentales, las adicciones etc.

Salvo excepcionales episodios, entre los que podemos destacar las dos grandes guerras mundiales, el crack financiero de 1930, no hubo un episodio que afectara tan radicalmente el estilo de vida y los circuitos económicos de una porción tan grande de la población mundial como la pandemia que estamos atravesando.

\section{El choque}

Mientras los responsables de la conducción política tratan de sortear este evento sin antecedentes (por suerte en el caso de Argentina con un grado de éxito notable), es necesario pensar fuertemente en las consecuencias económicas pero sobre todo sociales que debemos esperar ver emerger si entramos a la era "post-pandemia" sin habernos preparado, deberíamos revisar el ejemplo que nos dejó lo sucedido en los países del ex bloque socialista durante los años siguientes a la caída del Muro de Berlín (1989) y el brusco proceso de transformación que sufrió la URSS en su pasaje de sistema, por cierto también mencionado por Ernst Gellner (Anthropology and Politics - Blackwell Publishers Inc. 1995), en el que se desarticuló bruscamente el conjunto de normas imperantes de la noche a la mañana y se las reemplazó por otro totalmente diferente en el que nadie estaba demasiado seguro de su rol y de lo que se esperaba de cada quien, dando lugar a una gran cantidad de comportamientos adaptativos de carácter negativo (crimen organizado, alcoholismo, abuso de drogas, corrupción privada y estatal, etc.).

Lo que sabemos hoy (y esto cambia cada hora) sobre la salida de esta situación es que una vacuna o un remedio paliativo que permita "normalizar por completo la vida como la conocíamos puede tardar alrededor de un año, a lo que habría que agregar el tiempo que demoraría producir miles de millones de dosis y distribuirlas en todo el mundo.

Mientras tanto lo que debemos impedir es que se produzca una nueva colisión entre el sistema de metas/valores y los medios para alcanzarlos que tenemos los individuos que formamos esta sociedad, y esto me preocupa porque veo a mi alrededor que mientras nuestro sistema de 
creencias y valores permanece intacto, la industria cultural se ocupa de mantenerlo así a cada hora a través del sistema de multipantallas al que estamos expuestos, todo el que tenga una opinión educada al respecto de la situación económica en el corto y mediano plazo, expresa que las condiciones laborales y la economía en general se van a ver afectados poniendo en jaque los medios para continuar accediendo a las metas. Pensemos solamente en la industria del entretenimiento y ocio: cines, teatros, restaurants, bares, eventos musicales, eventos deportivos, convenciones, hotelería, centros vacacionales. en suma todo lo que implique grandes cantidades de público reunido en un mismo lugar es inimaginable por el momento, todo el que tenga un modo de vida basado en estas actividades enfrenta graves problemas, y solo estoy citando algunos al azar sin mencionar todos los que proveen servicios a estos.

\section{Lo Micro, lo Macro y lo Mega}

No es sencilla la tarea por delante, la crisis económica que nos dejó una nueva temporada de esta maravillosa serie de suspenso y super acción llamada Consenso de Washington, quedó en parte opacada por las consecuencias no deseadas de la excelente decisión de imponer aislamiento obligatorio para toda la población que no realice tareas esenciales. A pesar de los pitos y cornetas que hicieron sonar los medios que trabajan para el poder económico en contra de la medida, el cumplimiento hasta la fecha ha sido singular, un éxito compartido entre una población responsable y una conducción política que tuvo dos aciertos enormes en esta crisis: evaluar correctamente la situación y aplicar las medidas necesarias a pesar de los efectos indeseados. Sin embargo más tarde o más temprano hay que volver a la normalidad o mejor dicho ingresar en una "Nueva Normalidad".

No me parece muy aventurado, a la luz de todo lo que sabemos sobre esta enfermedad y los pronósticos para obtener una solución para ella, y las amenazas de una nueva pandemia (de similar origen zoonótico, características y resultados) a la vuelta de la esquina, decir que no estamos en presencia de cambios momentáneos en nuestras rutinas diarias sino de algo permanente que va a requerir urgente poner atención en tres planos: el plano de los cambios a introducir en el pequeño gesto de todos los días (lo micro), el plano de los cambios en las relaciones entre los actores económicos y las variables que impactan en el crecimiento (lo macro) y también en el plano de las relaciones internacionales que pasaron de ser importantes a vitales de un día para el otro, sobre todo para países periféricos (lo mega). 
El gobierno tiene que atender en primer lugar las especificidades que la pandemia impone en la salud desde luego, pero también y no menos importante en la higiene y seguridad de todas las tareas, tanto las productivas, como las de seguridad, justicia, educación y cultura, de la Administración Pública, legislativas, las relacionadas con el esparcimiento y educación, etc., en este aspecto hay transformaciones profundas que hacer sobre todo en lo referido protocolos sanitarios que deberán seguirse en los espacios públicos, y en los ambientes de trabajo, también habrá que mediar en la nueva realidad del "teletrabajo" y las adaptaciones que el Derecho Laboral debería encarar, pero sobre todo hay desafíos muy importantes que hacer en el plano de la conectividad (el acceso a internet) en el vasto territorio de la República y sobre todo en el acceso de una parte importante de a población a los conocimientos necesarios para integrarse adecuadamente a una Sociedad Red (para usar el término de Manuel Castells) que a partir de hoy ha alcanzado un nuevo nivel de profundidad.

También esta Administración tiene que volver a poner a la Argentina en el camino del crecimiento aún a pesar de todas las restricciones que impone el escenario micro, llevar a buen puerto las negociaciones con los acreedores de la Deuda Externa demencial que tomó el gobierno anterior (y respondiendo con buenas maneras y fresca sonrisa los "consejos" sobre como hacerlo de parte de los responsables de este descalabro, a riesgo de ser tildada de "resentida", "agresiva", "violenta" por los formadores hegemónicos de opinión pública, de no hacerlo), domesticar al siempre voraz sistema bancario, reconducir al gran empresariado argentino del verde pastizal de la especulación, la evasión, la fuga de divisas y la formación de precios inflacionaria que propicia el oligopolio cartelizado hacia los terrenos menos plácidos de la inversión, el riesgo y el pago en tiempo y forma de impuestos de un sistema capitalista que tanto pretenden defender. En el camino debe retomarse el liderazgo en tecnología que anhelábamos con el INVAP y transformar la matriz productiva para agregar cada vez más valor a las exportaciones nacionales.

Como si todo lo anterior no fuera una tarea titánica, en paralelo es clave el despliegue de una política de relaciones internacionales que estén muy en sintonía con los objetivos que debe perseguir el plano micro/macro. Desde luego es importante profundizar las relaciones con la mayor potencia mundial, China, pero también lo es darle nuevo impulso a un bloque de países sudamericanos que funcione unido y coordinado, y aproveche las oportunidades comerciales de complementarse, y que realice finalmente el sueño del Banco regional para darle un grado 
de independencia y soberanía sin precedentes al conjunto de países miembro. En este punto hay oportunidades importantes, el ocaso de la hegemonía mundial de Washington y los cambios de viento político en países como Brasil, Chile y Ecuador producto de una mala gestión de la pandemia, puede favorecer el ascenso de liderazgos más permeables a este tipo de alineamientos regionales que realmente trabajen en el crecimiento de la región y pongan un signo de pregunta sobre las morisquetas de saltimbanqui de la diplomacia de derecha del Mercosur de los últimos años que nos dejó de regalo el emocionante (al menos para el ex Canciller Faurie) acuerdo con la Unión Europea, un cachorro de dragón que si no estrangulamos antes que crezca, en unos años nos obligará renunciar a toda pretensión de desarrollo industrial pesado o liviano y a vivir bajo tierra para escapar de su aliento flamígero devastador.

Algunas de estas cosas ya estarían el 18 de Mayo de 2019 en la cabeza de los líderes políticos que hoy nos tocan, muchas otras no, el tiempo nos dirá cuántos de estos desafíos se sortean.

\section{Y ahora, nosotros...}

Con excepción de la gesta de Malvinas, no recuerdo en los últimos 50 años un episodio que nos haya interpelado tan profundamente, ni que nos haya puesto a todos y cada uno de los casi 45 millones de argentinos en una comunión tan íntima, habiendo identificado con tanta precisión el enemigo común para todos, como esta pandemia mundial de CoVid-19.

No es casual la referencia a Malvinas (en muchos aspectos) estamos en guerra, los soldados de esa guerra somos todos, algunos pelean en el frente, son los soldados del cuerpo médico que todos los días en un hospital y en una clínica, en un consultorio, defienden cada centímetro de cuerpo argentino, los aerotransportados de Aerolíneas Argentinas que traen repatriados 0 van a China a buscar armas y pertrechos estratégicos, la caballería blindada de fuerzas de seguridad que salen a la calle para cuidarnos. Otros nos quedamos en casa, siendo solidarios con nuestro grupo familiar y con el resto de nuestros compatriotas, todos por igual resistiendo, con mayor o menor esfuerzo, en condiciones mejores y peores, todos en la misma causa.

$Y$ en este ejército que integramos todos, el arma con que combatimos día tras día, la que nos protege de ceder a la tentación y a la desesperación es la responsabilidad, responsabilidad de observar todos los protocolos de limpieza que nos exige la hora, responsabilidad para cuidar que todos a nuestro alrededor lo hagan, responsabilidad en mantener la cordialidad, 
responsabilidad en ser pacientes cuando los nervios ya no soportan, responsabilidad de asistir al que solo no puede, responsabilidad de ser humanos.

Pero también hay dos responsabilidades que como ciudadanos me parece central exhibir, en primer lugar la responsabilidad de informar, casos de falta de esa responsabilidad informativa hay a todo nivel: desde el comunicador social que propaga una información sin chequear, por desidia o mala fe, pasando por el ciudadano que difunde esa misma información sin verificar, hasta un Presidente que dice en rueda de prensa que inyectarse desinfectantes o irradiarse con rayos UV puede ser efectivo en la lucha contra el virus. $Y$ en segundo lugar la responsabilidad de tomar una posición respecto de lo que viene. $Y$ lo que viene es una puja distributiva entre trabajadores y empleadores, que si bien hasta ahora fue grande, en el último mes se ha inyectado esteroides, en todo el mundo se ha despertado una vieja/nueva conciencia sobre la desigualdad, sobre quién es quién a la hora de generar riqueza y por más esfuerzos que hagan desde los sectores que concentran la mayor riqueza mundial es imposible disimular el hecho de que sin los trabajadores no hay riqueza, y aún así lo intentan. Para ello cuentan con poderosas herramientas como figuras del ámbito político, judicial, sindical y una maquinaria comunicacional fenomenal capaz de dejar aturdido al espectador más agudo hasta hacerle repetir que "la liberación de presos es parte de una ideología abolicionista" y no la aplicación de un régimen domiciliario de detención por motivos humanitarios para ser aplicado sobre población penitenciaria de acuerdo a una serie de parámetros muy bien definidos que garantizan que el grupo que goce se ese cambio de situación no represente un peligro para la sociedad, o que estamos atrapados en un Estado Policial total, o que los políticos deben bajarse primero los sueldos antes de modificar los impuestos o que la carga impositiva en Argentina es la más alta del mundo o que no hay que dejar el manejo de una pandemia en manos de infectólogos, que hay que levantar la cuarentena porque van a ser más los muertos producto de la paralización de la economía, y siguen las firmas...

Se trata en definitiva de tener la responsabilidad de desvelar, de correr el velo de ese aparato por todos los medios a nuestro alcance, valorar la veracidad de la información circulante, entender cuál es el objetivo del aparato, qué intereses persigue, a quién beneficia, en suma fijarse de qué lado de la mecha nos encontramos (parafraseando a Graciana Peñafort, que toma la frase de "Queso Ruso", tema escrito por Beilinson y Solari que cierra el disco "La Mosca y la Sopa"), porque no nos confundamos, la pandemia no puso en espera la discusión 
de la distribución de la riqueza, la pandemia la aceleró, y ahora viajamos en el Delorean de Marty MacFly a 88 millas por hora rumbo a un futuro tan incierto como instantáneo, en el que vamos a necesitar repasar el pasado. 